\title{
From COVID-19 or because COVID-19?
}

\section{Guglielmo M. Actis Dato MD (1)}

Department of Cardiac Surgery, Ospedale Mauriziano "Umberto I", Turin, Italy

\section{Correspondence}

Guglielmo M. Actis Dato, Department of Cardiac Surgery, Ospedale Mauriziano di Torino, Largo Turati, Turin 10125, Italy.

Email: actisdato.g@gmail.com

\begin{abstract}
Infections and pandemics will condition us in an increasingly predominant way regarding diagnostic, medical, and surgical activities in all specialist areas. Particularly cardiovascular disease represents an important field also during other health crisis like COV19 pandemia. A common strategy in the future, to cohabit with pandemic events and to be able to continue an elective and not only emergency cardiac surgery program represents an imperative.
\end{abstract}

\section{KEYWORDS}

cardiac surgery, COVID-19
Rosati et al. ${ }^{1}$ highlight some aspects to which we will have to get used more and more in the near future: infections and pandemics will condition us in an increasingly predominant way regarding diagnostic, medical, and surgical activities in all specialist areas; and this particularly in cardiovascular one.

During the first surge of COVID-19 in early 2020, the Italian National Health System had to make a huge effort to meet the changing needs for hospitalization and the need for assistance in intensive care which until then was mainly reserved for patients receiving highly specialized care such as cardiovascular surgery. ${ }^{2}$

Moreover, in the same period, the Italian Society of Cardiac Surgery $(\mathrm{SICCH})$ produced a position paper regarding the management of patients requiring surgery for cardiac diseases. ${ }^{3}$

This has inevitably led to the need to block or postpone numerous nonemergency interventions and procedures in the cardiosurgical and cardiology field.

Unfortunately, after few months, facts have been shown that one dies not only "because COVID-19" but also "from COVID-19!"

A recent update of a study analyzing US mortality between March 2020 and January 2021, reported 22.9\% more than expected deaths, partly explained by COVID-19. Statistical analysis shows surges in excess deaths that change in timing and duration across different states in the United States. Increased mortality from nonCOVID-19 causes was also observed. An excess of deaths not attributed to COVID-19 could of course reflect either immediate or delayed mortality from undocumented COVID-19 infection, or nonCOVID-19 deaths secondary to the pandemic, (delayed care, behavioral health crises). But an undoubted increase in death rates was observed during surges due to several non-COVID-19 diseases such as heart disease. ${ }^{4}$

An observational study during lockdown (March-April 2020) in Germany shoved a decreased activity on Cath Lab activity (-35\%) and increased cardiac and cardiovascular mortality (+12\% and $+8 \%)$ if compared with the same period of 2019.

Possible reasons were: patient-based anxiety to come to the hospital reinforced by the order to "stay at home" but also the triage of patients according to priority levels, with patients with assumed elective procedures being put on a waiting list, has kept patients from urgently seeking medical attention for chest pain. ${ }^{5}$

The roadmap proposed by the authors at an early stage of the pandemic and in a European geographical area where the spread of the virus was particularly aggressive, suggests how it is possible, even in emergency conditions, to continue to provide our patients with an adequate therapeutic and surgical answer in terms of results and comfort for the patient. ${ }^{1}$

The four steps proposed by Rosati et al. in this very early phase of the pandemic event, with current knowledge and improved diagnostic skills, can perhaps be simplified by possibly replacing the use of CT scan with lung ultrasound that seems to provide an adequate, less expensive and faster way for a screening process. ${ }^{6,7}$

Nevertheless, in the future, the need to cohabit with pandemic events and to be able to continue an elective and not only emergency cardiac surgery program represents an imperative.

\section{CONFLICT OF INTEREST}

The author declares that there is no conflict of interest. 


\section{ORCID}

Guglielmo M. Actis Dato (D) https://orcid.org/0000-0003-4209-2866

\section{REFERENCE}

1. Rosati $\mathrm{F}$, Muneretto $\mathrm{C}$, Baudo $\mathrm{M}$, et al. A multicentre roadmap to restart elective cardiac surgery after COVID-19 peak in an Italian epicenter. J Card Surg. 2021, in press.

2. Gruppo di Lavoro ISS Cause di morte COVID-19, Gruppo di lavoro Sovrintendenza sanitaria centrale - INAIL, ISTAT. COVID-19: interim report on definition, certification and classification of causes of death. Updating Rapporto ISS COVID-19 n. 49/2020. 2021.

3. Bonalumi G, Di Mauro M, Garatti A, Barili F, Parolari A, Gerosa G. Pandemia da COVID-19 e Chirurgia Cardiaca: position paper della Task Force della Società Italiana di Chirurgia Cardiaca COVID-SICCH. G Ital Cardiol. 2020;21(6):396-400. https://doi.org/10.1714/3359.33320

4. Woolf SH, Chapman DA, Sabo RT, Zimmerman EB. Excess deaths from COVID-19 and other causes in the US, March 1, 2020, to January 2, 2021. JAMA. 2021;325(17):1786-1789. https://doi.org/ 10.1001/jama.2021.5199
5. Nef HM, Elsässer A, Möllmann H, et al. Impact of the COVID-19 pandemic on cardiovascular mortality and catheterization activity during the lockdown in central Germany: an observational study. Clin Res Cardiol. 2021;110:292-301.

6. Soldati G, Smargiassi A, Inchingolo R, et al. Is there a role for lung ultrasound during the COVID-19 pandemic? J Ultrasound Med. 2020; 39(7):1459-1462. https://doi.org/10.1002/jum.15284

7. Nouvenne A, Zani MD, Milanese G, et al. Lung ultrasound in COVID-19 pneumonia: correlations with chest CT on hospital admission. Respiration. 2020;99:617-624. https://doi.org/10.1159/ 000509223

How to cite this article: Actis Dato GM. From COVID-19 or because COVID-19? J Card Surg. 2021;36:3317-3318.

https://doi.org/10.1111/jocs.15774 